\title{
Viewpoint
}

\section{Reducing maternal mortality in Nigeria: addressing maternal health services' perception and experience}

\author{
Beatrice Wuraola Ope ${ }^{1}$ \\ 1 Department of Social Statistics and Demography, University of Southampton, Southampton, UK \\ Keywords: maternal mortality, healthcare, nigeria \\ https://doi.org/10.29392/001c.12733
}

\section{Journal of Global Health Reports}

Vol. 4, 2020

\begin{abstract}
Despite efforts targeted at addressing maternal deaths across national and sub-national levels, maternal mortality ratio has remained high in Nigeria in the last two decades, with the country currently accounting for about $20 \%$ of global maternal deaths. While improving overall quality of healthcare is crucial to addressing the high maternal deaths, some country-specific issues need to be explored. This paper highlights the need to understand and address the perception and experiences of maternal services particularly at point of delivery, as this is imperative towards increasing the utilization of maternal health facilities in a multicultural setting like Nigeria. The focus should not only be on why women do not accept healthcare services, but why health facilities do not provide the services that women will accept. This approach to assessing quality of healthcare is necessary to inform relevant policy and public health response in the country.
\end{abstract}

Maternal mortality ratio (MMR) in several low-and-middle-income countries is alarming, with about $34 \%$ of global maternal deaths occurring in Nigeria and India alone. ${ }^{1}$ According to the World Health Organization (WHO), the MMR of Nigeria is 814 (per 100,000 live births). ${ }^{1}$ The lifetime risk of a Nigerian woman dying during pregnancy, childbirth, postpartum or post-abortion is 1 in 22 , in contrast to the lifetime risk in developed countries estimated at 1 in $4900 .^{2}$ Current evidence suggests that the high rate of maternal and neonatal mortality in Nigeria is linked to the three forms of maternal delay proposed by Thaddeus and Marine. ${ }^{3,4}$ These barriers include delay in making decision to seek maternal health care; delay in locating and arriving at a medical facility; and delay in receiving skilled pregnancy care when the woman gets to the health facility. ${ }^{2-4}$

To address the challenges associated with the three delays which prevent women from receiving adequate timely maternal health care, some studies recommended improving access to skilled birth attendance (SBA) especially through better quality primary health care (PHC). This is because Nigeria has about 34,000 PHCs (entry point level) covering all health wards and hard-to-reach communities. ${ }^{3,4}$ Hence, improving the accessibility, availability, affordability and care quality in PHCs will most likely reduce the high rate of neonatal and maternal mortality in Nigeria. ${ }^{2}$ Another study stated that maternal mortality in Nigeria would reduce if there is an improvement in the quality of care provided within tertiary health facilities (second-level referral). ${ }^{5}$ The authors emphasized that the inability to get quality health services in most Nigerian health institutions contribute greatly to the high maternal deaths in the country. ${ }^{5}$ Additionally, the WHO associated the high prevalence of maternal death in Nigeria to inequalities in access to health services as women in resource-poor settings are least likely to receive adequate, timely and affordable health ser- vices by skilled personnel compared to their counterparts in more developed countries. ${ }^{2}$

Although the evidence towards reducing maternal mortality through access to skilled pregnancy care are largely relevant, it remains inadequate in ensuring a substantial decline in maternal deaths in Nigeria. Improving the quality of health services goes beyond assessing only the supply aspect of care. Some authors noted that even if the standard of services in Nigerian primary, secondary or tertiary health facilities is improved, maternal mortality may still be high. ${ }^{6}$ This is because an increase in the quality of care provided at a health institution does not always translate to an increase in utilization of the health services by women. ${ }^{7-9}$ Most times, the choices that these women make in the utilization of a health facility are based on their perception of care, and not on the actual quality of care being delivered.

In Ota, Ogun State, south-western Nigeria, for instance, several women believe that delivering in a noninstitutional setting is better than in a modern facility because traditional birth attendants show more concern and compassion than skilled birth attendants. ${ }^{10}$ This perhaps shows a clear distinction between actual quality of care provided and perceived quality of care; even if the modern health facilities in Ota have sufficient health experts with internationally recognized good practice, the maternal deaths might still be on the increase, because women's perception of 'quality' influences health service utilization. Similarly, in Northern Nigeria, Puddah (female seclusion) is very common, where women are isolated and encouraged to give birth at home. Many in these settings believe that allowing an outsider help with delivery could be disrespectful. ${ }^{11}$ Thus, even if maternal health institutions exist in this region, it might not improve health outcomes because of people's beliefs and culture. Moreover, raising awareness on the existence of a maternal health facility, making it accessible and af- 
fordable does not always result to its utilization. For example, in Giwa Local Government Area (LGA) of Kaduna State Nigeria, despite living close to a health facility with free maternal health services, majority of the women were not utilizing the facility for child delivery. ${ }^{12}$ One of the reasons for the poor use of formal health system in that community is the belief that health care providers have a negative attitude; consequently, many women would rather give birth at home or at a traditional health center. ${ }^{12}$

In Esan and Etsako LGAs of Edo State Nigeria, some authors reported that perception of maternal healthcare quality plays a major role is the use of health services, with $25 \%$ of women, which is perhaps under-reported, in that community delivering at home even when a primary healthcare facility is located close to where the women reside. ${ }^{3}$ In addition, a qualitative study in the same LGAs of Edo State revealed that some women prefer traditional birth attendants to primary health care providers because the former are friendlier (similar to the experience at Ota) and offer native medicine (traditional herbs) which is believed to be the best form of medication during childbirth. ${ }^{13}$ Some women who do not use modern maternal health services in that area believe that the place a woman gives birth is inconsequential because it is only God that sustains during delivery. ${ }^{13}$

Therefore, apart from the quality of services provided by a health facility, patients' experience and perception of quality care determine the utilization of a health facility. ${ }^{14}$ This could be partly responsible for the low antenatal care (ANC) coverage in Nigeria, where six out of ten Nigerian women receive ANC during pregnancy, and majority (twothirds) never return to deliver their baby at a health institution. ${ }^{15}$ In fact, a woman's perception of 'quality care' might even influence another person's health-seeking behaviour. ${ }^{16}$ For instance, if a woman's experience of care during a normal delivery was negative, other women whom she might have told of such experience might delay in deciding to seek care (even when standard quality services are provided at the health facility) thereby increasing the likelihood of birth complications and maternal death.

Building on the discussion above, a holistic approach to studying quality of care which includes the supply (provision of care) and demand (experience of care) aspect, will be necessary for improving maternal health in Nigeria (Figure 1). ${ }^{17}$ To get a broader understanding of health care quality, there is need to measure both hospital quality and the woman's experience of that quality; and then make comparisons, to reveal barriers to accessing care as well as priority areas for health interventions. ${ }^{16,17}$ This approach of assessing maternal healthcare quality could even speed up the achievement of the Sustainable Development Goal (SDG) of an annual $7.1 \%$ decline in maternal mortality in Nigeria. ${ }^{1} \mathrm{~A}$ great way of doing this will be to consider both qualitative and quantitative research approach when measuring the quality of a health facility, as quantitative studies alone may not capture in detail how women experience care as most of the questions are predetermined and close-ended. ${ }^{16}$ Using a combination of several data collection methods such as facility records, focus group discussions, providers interviews, observation, community surveys, case notes and indepth interviews will be effective in assessing the quality of maternal care in Nigeria. ${ }^{17}$

In conclusion, this article is not aimed at diverting focus from improving the quality of healthcare services provided in facilities, as this remains highly important in determining health outcomes, but to emphasize the need for understanding and addressing women's experience and perception of quality care, particularly in Nigeria and other similar settings. Unfortunately, there is a dearth of published research on patient-centred models of assessing health quality in Nigeria which could have been a major source of evidence-based recommendations across the country. Further extensive research is highly recommended to create a robust understanding of women's perception of quality maternal health care in Nigeria. This is relevant for the health sector and indeed the policymakers who are in position to make necessary decisions to reduce avoidable maternal deaths in the country.

Acknowledgements: The author wishes to thank Dr Kristine Nilsen, Dr Heini Väisänen and Professor Zoe Matthews for their intellectual support. Thanks to the Commonwealth Scholarship Commission in the UK for supporting the author's study at the University of Southampton, UK.

\section{Funding: None}

Authorship contributions: BWO conceived, drafted and wrote the manuscript.

Competing interests: The author completed the Unified Competing Interest form at www.icmje.org/coi_disclosure.pdf (available upon request from the corresponding author), and declare no conflicts of interest.

\section{Correspondence to:}

Beatrice Wuraola Ope

Department of Social Statistics and Demography

University of Southampton

Southampton, UK

opebeatrice9@gmail.com 


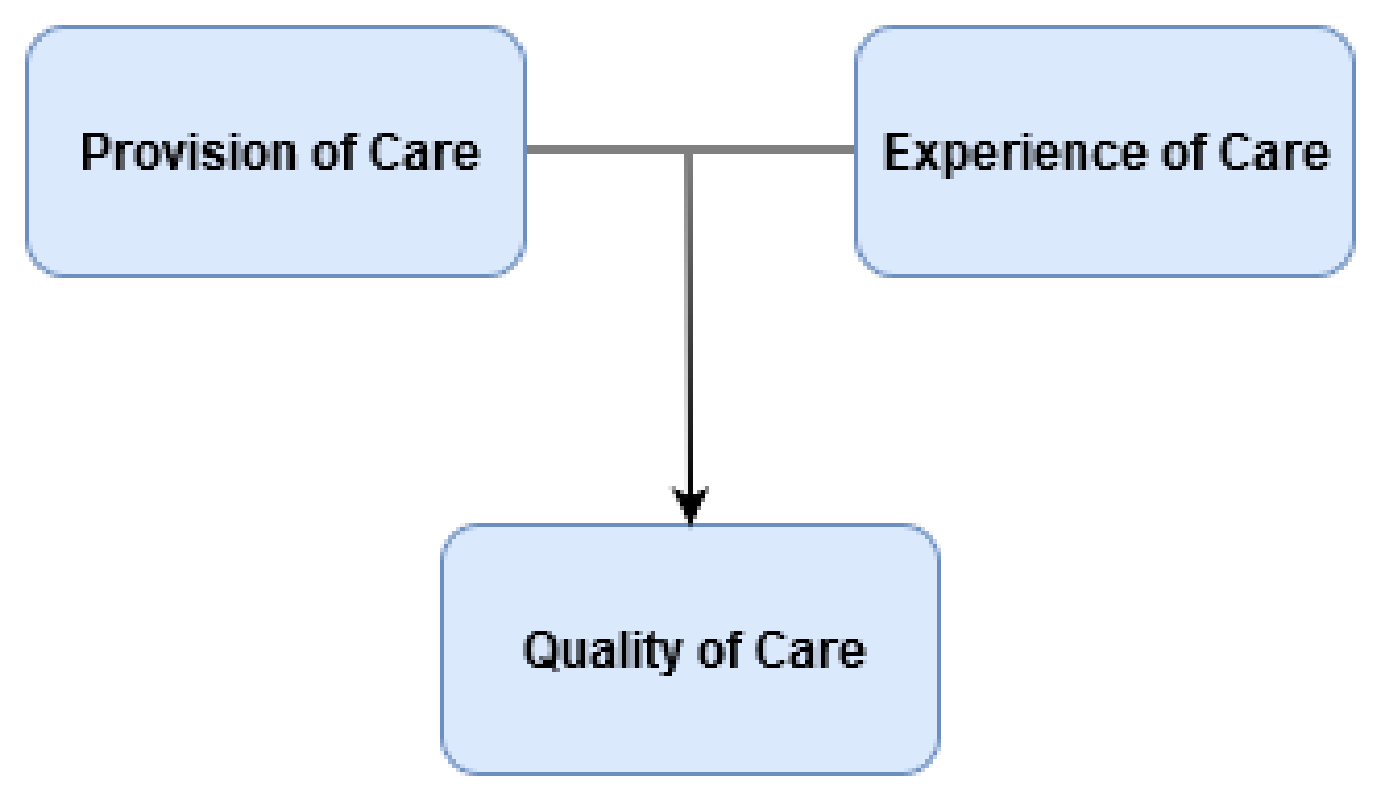

Figure 1. Framework for assessing quality of institutional-delivery services

Adapted from Hulton's framework for the evaluation of quality of care in maternity services. ${ }^{17}$ 


\section{REFERENCES}

1. World Health Organization. Trends in Maternal Mortality: 1990 to 2015: Estimates Developed by WHO, UNICEF, UNFPA, World Bank Group and the United Nations Population Division. Geneva https://reliefwe b.int/report/world/trends-maternal-mortality-1990-2 015-estimates-who-unicef-unfpa-world-bank-groupand. Accessed December 19, 2019.

2. World Health Organization. Sexual and Reproductive Health. Maternal Health in Nigeria: Generating Information for Action. https://www.who.int/reproduct ivehealth/maternal-health-nigeria/en/. Accessed January 7, 2020.

3. Okonofua F, Ntoimo L, Ogungbangbe J, Anjorin S, Imongan W, Yaya S. Predictors of women's utilization of primary health care for skilled pregnancy care in rural Nigeria. BMC Pregnancy and Childbirth. 2018;18:1-15. doi:10.1186/s12884-018-1730-4

4. Yaya S, Okonofua F, Ntoimo L, et al. Increasing women's access to skilled pregnancy care to reduce maternal and perinatal mortality in Rural Edo State, Nigeria: A randomized controlled trial. BMC Global Health Research and Policy. 2018;3:1-10. doi:10.1186/s 41256-018-0066-y

5. Oladapo T, Adetoro O, Ekele A, Chama C, Etuk J, Aboyeji P, et al. When getting there is not enough: A nationwide cross-sectional study of 998 maternal deaths and 1451 near-misses in public tertiary hospitals in a low-income country. BJOG. 2015;123:928-938. doi:10.1111/1471-0528.13450

6. Yaya S, Bishwajit G, Uthman A, Amouzou A. Why some women fail to give birth at health facilities: A comparative study between Ethiopia and Nigeria. PLoS One. 2018;13:1-11. doi:10.1371/journal.pone.01 $\underline{96896}$

7. Lubbock A, Stephenson B. Utilization of maternal health care services in the department of Matagalpa, Nicaragua. Rev Panam Salud Publica. 2008;24:75-84. $\underline{\mathrm{d}}$ oi:10.1590/S1020-49892008000800001

8. Babalola S, Fatusi A. Determinants of use of maternal health services in Nigeria - looking beyond individual and household factors. BMC Pregnancy and Childbirth. 2009;9:1-13. doi:10.1186/1471-2393-9-43
9. Srivastava A, Avan BI, Rajbangshi P, Bhattacharyya $S$. Determinants of women's satisfaction with maternal health care: A review of literature from developing countries. BMC Pregnancy and Childbirth. 2015;15:1-12. doi:10.1186/s12884-015-0525-0

10. Azuh D, Azuh A, Iweala E, Adeloye D, Akanbi M, Mordi R. Factors influencing maternal mortality among rural communities in southwestern Nigeria. International Journal of Women's Health. 2017;9:179-188. doi:10.2147/IJWH.S120184

11. Wall L. Dead Mothers and Injured Wives: The Social Context of Maternal Morbidity and Mortality among the Hausa of Northern Nigeria. Studies in Family Planning. 1998;29:341-359. doi:10.2307/17224 $\underline{8}$

12. Idris HS, Sambo NM, Ibrahim SM. Barriers to utilization of maternal health services in a semiurban community in northern Nigeria: The clients' perspective. Nigerian Medical Journal. 2013;54:27-32. doi:10.4103/0300-1652.108890

13. Ntoimo FC, Okonofua FE, Igboin B, Ekwo C, Imongan $\mathrm{W}$, Yaya $\mathrm{S}$. Why rural women do not use primary health centres for pregnancy care: Evidence from a qualitative study in Nigeria. BMC Pregnancy Childbirth. 2019;19:1-13. doi:10.1186/s12884-019-243 $\underline{3-1}$

14. Emelumadu OF, Onyeonoro UU, Ukegbu AU, Ezeama NN, Ifeadike CO, Okezie OK. Perception of quality of maternal healthcare services among women utilising antenatal services in selected primary health facilities in Anambra State, Southeast Nigeria. Niger Med J. 2014;55:148-155. doi:10.4103/0300-1652.1296 $\underline{53}$

15. National Population Commission [Nigeria] and ICF International. Nigeria Demographic and Health Survey 2013. Rockville, Maryland, USA: National Population Commission and ICF International; 2014.

16. Hanefeld J, Powell-Jackson T, Balabanova D. Understanding and measuring quality of care: Dealing with complexity. Bull World Health Organ. 2017;95:368-374. doi:10.2471/BLT.16.179309

17. Hulton AL, Mathews Z, Stones RW. A Framework for the Evaluation of Quality of Care in Maternity Services. Southampton. University of Southampton; 2000. 